\section{Atypical diabetes: clarifying the muddy waters}

We are writing this letter in response to Steenkamp and collegues' recent review article. ${ }^{1}$ We have several concerns about the content of this review particularly in the context of the Canadian diabetes landscape.

There is no discussion in the review around the controversy that surrounds the diagnoses of ketosis-prone diabetes and latent-autoimmune diabetes of adulthood (LADA). Many clinicians believe these are not separate entities but are within the spectrum of type 2 diabetes and type 1 diabetes, respectively. There is no mention of the occurrence of diabetic ketoacidosis in both adults and children with type 2 diabetes. This has been well published over the last two decades in both adults and children. ${ }^{2-4}$

The authors use somewhat dated terminology, such as "the classic juvenile form of diabetes." Both the Canadian Diabetes Association and the American Diabetes Association discontinued the use of this terminology more than 15 years ago.

The Canadian Diabetes Association has worked hard to provide useful agespecific definitions and management guidelines; these are available online for health care providers. ${ }^{5}$

The authors state that metformin is first line therapy for most patients with type 2 diabetes. This is not consistent with the Canadian Diabetes Association Clinical Practice Guidelines where lifestyle modification is first line therapy in children and also in adults. Perhaps it should have been clarified that metformin would be the first-line pharmacotherapeutic agent.

Mention of the polymorphism of the HNF $1 \alpha$ gene found in the Oji-Cree of northeastern Manitoba and northwestern Ontario is warranted. This polymorphism contributes to the development of type 2 diabetes in the Oji-Cree, who have among the highest reported rates of type 2 diabetes in both adults and youth. ${ }^{6,7}$ Regional differences are important to reinforce to ensure optimal diagnoses and intervention.

Elizabeth Sellers MD MSc, Seth Marks MD MSc, Celia Rodd MD MSc, Randy Wicklow MD MSc, Heather Dean MD

Section of Pediatric Endocrinology and Metabolism (Sellers, Marks, Rodd, Wicklow, Dean), Department of Pediatrics and Child Health, University of Manitoba, Winnipeg, Man.

\section{References}

1. Steenkamp DW, Alexanian SM, Sternthal E. Approach to the patient with atypical diabetes. CMAJ 2014; 186:678-84.

2. Newton CA, Raskin P. Diabetic ketoacidosis in type 1 and type 2 diabetes mellitus. Arch Intern Med 2004;164:1925-31.

3. Rewers A, Klingensmith G, Davis C, et al. Presence of diabetic ketoacidosis at diagnosis of diabetes mellitus in youth: the Search for Diabetes in Youth Study. Pediatrics 2008;121:e1258-66.

4. Amed S, Dean HJ, Panagiotopoulos C, et al. Type 2 diabetes, medication-induced diabetes and monogenic diabetes in Canadian children: a prospective national surveillance study. Diabetes Care 2010;33:786-91.

5. Clinical practice guidelines. Toronto: Canadian Diabetes Association; 2014. Available: www.diabetes.ca /clinical-practice-education/clinical-practice-guidelines (accessed 2014 Nov. 13).

6. Hegele RA, Zinman B, Hanley AJ, et al. Genes, environment and Oji-Cree type 2 diabetes. Clin Biochem 2003;36:163-70.

7. Dean HJ, Young TK, Flett B, et al. Screening for type-2 diabetes in aboriginal children in northern Canada. Lancet 1998;352:1523-4.

CMAJ 2014. DOI:10.1503/cmaj.1140088

\section{Author response}

This article was written for the practising primary care clinician, who may occasionally take care of a patient with diabetes who doesn't seem to fit into our typical diabetes classification paradigm. It is not a comprehensive review of the topic for the expert practising endocrinologist.

LADA is a slowly progressive form of type 1a diabetes, and while it may not be distinct from type 1 diabetes, it has certain autoimmune and phenotypic features that distinguish it from childhood type 1 diabetes. Ketosis prone diabetes (KPD) is not simply type 2 diabetes presenting with ketoacidosis. This group of patients is still poorly understood, and much work needs to be done in furthering our understanding of the basic pathophysiology of this heterogeneous group of diabetes. Emerging metabolomics data suggest that in individuals within certain subsets of 
$\mathrm{KPD}$, a distinctive novel pathogenic process of defective energy production and ketosis may be at play.

Given space limitations, we were unable to describe specific populations with monogenic diabetes, but we hope that our focused discussion of HNF1A monogenic diabetes will stimulate consideration of this type of diabetes.

We agree that regional variation and location of practice are highly relevant. For example, in our hospital, which serves a large, underserved, heterogeneous urban population, ketosis-prone diabetes is the most common reason for admission to the intensive care unit with ketoacidosis. Type 1a diabetes is less common in our particular setting.

Naturally, diet and lifestyle modification form the cornerstone of all diabetes therapeutics. We acknowledge that controversies surrounding diabetes classification continue to exist, but recognition of a possible atypical diabetes phenotype is an important part of primary diabetes care.

\section{Devin Steenkamp MD, Sara Alexanian} MD, Elliot Sternthal MD

Section of Endocrinology (Steenkamp, Alexanian, Sternthal), Diabetes and Nutrition, Boston University School of Medicine, Boston, Mass.

CMAJ 2014. DOI:10.1503/cmaj.1140089

\section{Beyond resuscitate and do- not-resuscitate}

We applaud Hebert and Selby ${ }^{1}$ for examining the difficulties of responding to iatrogenic or potentially readily reversible critical incidents in patients with a do-not-resuscitate order. Several Canadian health authorities have already replaced do-not-resuscitate orders with more nuanced medical order frameworks (Goals of Care Designations $^{2}$ in Alberta and Medical Orders for Scope of Treatment ${ }^{3}$ at Fraser Health, BC) to better reflect patient values and medical care appropriate to their context.

These medical orders are determined through a process of communication between a patient, surrogate decision-makers and health care providers. The orders convey information about the types of interventions to be used or withheld, the location of care and most importantly the general intention of care. System-wide policies and procedures ensure that the order and documented discussions travel with the patient. These frameworks are implemented with advance care planning initiatives ${ }^{4}$ normalizing early reflection and communication, which can assist in health care decision-making.

Although not a panacea for ethical dilemmas, such frameworks greatly inform decision-making. They are an improvement over binary resuscitate or do-not-resuscitate orders and prior conversation details buried in health records.

\section{Jessica Simon MB ChB, Eric Wasylenko} MD BSc MHSc, Doris Barwich MD Physician Consultant, Advance care planning and Goals of Care Designations, Alberta Health Services, Calgary Zone, and Division of Palliative Medicine, Department of Oncology and Department of Internal Medicine, University of Calgary (Simon), Calgary, Alta.; Provincial Medical Advisor, Advance Care Planning/Goals of Care Designation Initiative, Alberta Health Services; Division of Palliative Medicine, Department of Oncology, University of Calgary; John Dossetor Health Ethics Centre, University of Alberta, (Wasylenko) Edmonton, Alta.; Executive Director, BC Centre for Palliative Care (Barwich), British Columbia, Vancouver BC

\section{References}

1. Hébert PC and Selby D. Should a reversible, but lethal, incident not be treated when a patient has a do-not-resuscitate order? CMAJ 2014;186:528-30.

2. Advance care planning and goals of care designation. Calgary (AB): Alberta Health Services; 2014. Available: https://extranet.ahsnet.ca/.../clp-advance -care-planning-hcs-38-01-procedure. pdf (accessed 2014 Apr. 28)

3. Medical Orders for Scope of Treatment (MOST) and Advance Care Planning (ACP) [policy]. Surrey (BC): Fraser Health; 2012. Available: www.fraserhealth.ca $/$ media/Medical $\% 20$ Orders $\% 20$ for $\% 20$ Scope $\% 20$ of $\% 20$ Treatment $\% 20 \% 28$ MOST $\% 29 \% 20$ and $\%$ 20Advance $\% 20$ Care $\% 20$ Planning $\% 20 \% 28 \mathrm{ACP} \%$ 29.pdf (accessed 2014 Apr. 28).

4. Conversations matter - It's about decisions and how we care for each other. Calgary (AB): Alberta Health Services. Available: www.conversationsmatter.ca (accessed 2014 Apr. 28)

CMAJ 2014. DOI:10.1503/cmaj.114-0092

\section{The authors respond}

We thank Simon and colleagues ${ }^{1}$ for their response to our article. ${ }^{2} \mathrm{We}$ applaud the initiatives they describe. We think it important that they combine the Goals of Care Designations with the documentation of the discussions leading to the decisions made by each individual patient. We are encouraged by the uptake of these ideas in many jurisdictions and look forward to their adoption across Canada.

Philip C. Hébert MD, Debbie Selby MD Department of Family and Community Medicine (Hébert), University of Toronto; and Sunnybrook Health Sciences Centre (Selby), Toronto, Ont.

\section{References}

1. Simon J, Wasylenko E, Barwich D. Beyond resuscitate and do-not-resuscitate [letter]. CMAJ 2014; 186:1398.

2. Hébert PC, Selby D. Should a reversible, but lethal, incident not be treated when a patient has a do-not-resuscitate order? CMAJ 2014;186:528-30.

\section{CMAJ 2014. DOI:10.1503/cmaj.114-0093}

\section{About bloody time}

Coincidentally, I read Dr. Shuchman's article $^{1}$ regarding the risks of iron deficiency with frequent blood donation while I was laying in a chair in Toronto donating whole blood. I am a frequent blood donor myself, and over the last year I have watched with growing trepidation the everdecreasing level of my hemoglobin at the point of donation. A course of iron supplementation seems to have done the trick, and I am actually feeling quite a bit more energetic as well. I am happy to hear that Canadian Blood Services will be piloting routine ferritin testing, although there is some recent evidence suggesting that reducing body iron stores may have beneficial effects on blood pressure, blood glucose and other metabolic parameters. ${ }^{2}$ In the absence of frank anemia, one wonders if there is an optimal ferritin level which balances the potential for chronic disease prevention and the risk of fatigue. Hopefully, future studies will guide us in this regard.

\section{Edward S. Weiss MD}

Family physician, Toronto, Ont.

\section{References}

1. Shuchman M. Frequent blood donors risk iron deficiency. CMAJ. 2014;186:817.

2. Houschyar KS, Lüdtke R, Dobos GJ, et al. Effects of phlebotomy-induced reduction of body iron stores on metabolic syndrome: results from a randomized clinical trial. BMC Medicine 2012, 10:54.

CMAJ 2014. DOI:10.1503/cmaj.1140090 